\title{
Diversity Analysis in Guizotia abyssinica (L. f.) Cass. Germplasms Collected from Ethiopia
}

\author{
Birhanu Mengistu ${ }^{1, *}$, Wosene Gebrselassie ${ }^{2}$, Tesfaye Disasa ${ }^{3}$ \\ ${ }^{1}$ Holeta Agricultural Research Center, Ethiopian Institute of Agricultural Research, Addis Ababa, Ethiopia \\ ${ }^{2}$ Department of Horticulture and Plant Science, University of Jimma, Jimma, Ethiopia \\ ${ }^{3}$ National Agricultural Biotechnology Research Center, Ethiopian Institute of Agricultural Research, Addis Ababa, Ethiopia \\ Email address: \\ yesilase07@gmail.com (B. Mengistu),wosish@yahoo.com (W. Gebrselassie), tesfayedisasa@yahoo.com (T. Disasa) \\ ${ }^{*}$ Corresponding author
}

\section{To cite this article:}

Birhanu Mengistu, Wosene Gebrselassie, Tesfaye Disasa. Diversity Analysis in Guizotia abyssinica (L. f.) Cass. Germplasms Collected from Ethiopia. Chemical and Biomolecular Engineering. Vol. 5, No. 1, 2020, pp. 8-14. doi: 10.11648/j.cbe.20200501.12

Received: December 15, 2019; Accepted: December 26, 2019; Published: January 7, 2020

\begin{abstract}
Noug Guizotia abyssinica (L. f.) Cass is an ancient and underutilized oilseed. In Ethiopia it is among the most important oilseed in terms of area coverage, volume of production and the main source of edible oil for local consumption. Determining the genetic diversity is fundamental in any noug improvement program. The objective of this study was to find out the extent and pattern of genetic diversity among noug genotypes. The experiment was carried out at Holetta, Ethiopia from June to December 2017 using 98 accessions and two improved varieties. The treatments were arranged in $10 \times 10$ simple lattice designs. Analysis of variance and variance components were estimated using SAS 9.3. The analysis of variance revealed significant difference $(p<0.05)$ among the genotypes for all the traits. The highest phenotypic coefficient of variation $(78.8)$ was observed for number of heads per plant. Genotypic coefficient of variation ranged from 2.6 for yield per plot to 72.3 for number of heads per plant. The highest broad sense heritability (90.1) was observed for oil content and the lowest value $(37.5 \%)$ noted for number of primary branch. The genetic gain ranged from 3.8 for yield per plot to 136.7 for number of head per plant. The study indicates the presence of genetic variability among the tested genotypes which implies the possibility for future improvement and the need for the initiation of a planned breeding and conservation programs by considering all growing areas as important source of desirable traits.
\end{abstract}

Keywords: Diversity, Ethiopia, Genotypes, Guizotia Abyssinica

\section{Introduction}

Noug (Guizotia abyssinica (L. f.) Cass.) is an indigenous and underutilized oil seed mainly cultivated in Ethiopia and India, which is grown for its edible oil and seed. In Ethiopia it is grown by over 0.77 million small holder farmers cultivated on 0.25 million hectare of land with production and productivity of 2.96 million tons and 1.1 tone $\mathrm{ha}^{-1}$ respectively. It is the second widely grown oil seed next to sesame in the country [1].

Ethiopian farmers prefer to grow noug because of the capability of the crop to grow and giving a good seed yield under low soil fertility, moisture stress and poor management practices. In addition, noug tolerate crop pests and has fewer diseases and insect pests than other oilseeds. Furthermore, noug is suitable for soil conservation and rehabilitation. It is the main source of edible oil for local consumption in Ethiopia [2]. The pale yellow with nutty taste and pleasant odor noug oil is the primary choice for most Ethiopians.

Although Ethiopia is the center of origin and diversity for noug; it has remained among the poor yielder crop in the country. Its production and productivity is plagued by a number of critical drawbacks. The major factors are indeterminate growth habit leading to seed shattering, selfincompatibility, genetically low yielding characteristics, lodging, less or low response to management inputs, difficulty of pollination behavior, disease, insect and parasitic weeds. The availability of limited genetic information and semi domesticated nature of the crop has been an obstacle for further improvement programs [3]. 
Genetic diversity is the variation of heritable characteristics present in a population of the same species. It includes all the variability occurring among different genotypes which is the base for breeders to develop new and improved cultivars [4]. Assessment of genetic diversity provides critical information about substantial genetic divergence and serves as a platform for specific breeding objectives [5]. Even if there is no any accurate assessment regarding the level and patterns of diversity; it can be carried out using morphological, biochemical, molecular and cytological characterization [6]. But the first three markers are the most commonly used methods to evaluate genotypes, breeding lines and segregating populations. Morphological markers are the earliest and oldest markers based on phenotypic appearance considered as the first step in the genetic diversity assessment. They are inexpensive, simple to score and easy to apply for estimating genetic diversity $[7,8]$. They play a major role in studying and characterizing germplasms since it requires no complicated laboratory facilities and procedures.

Diversity studies using morphological markers have been carried out for the assessment of noug genotypes [3, 9]. High variability was observed between noug genotypes and Ethiopia germplasms are considered as good source for high yield, late maturity, bold seed, resistance to water logging and drought [2]. Other authors also reported that Ethiopian noug genotypes have a high amount of variation for morphological traits and other breeding attributes [10]. Significant genetic variability for morphological traits was similarly reported [11]. Phenotypic and genotypic coefficients of variations; heritability and genetic advance are the commonly used genetic parameters.

Noug has received little attention by scientists and considered as underutilized or orphan crop; which is an obstacle for further improvement programs [3]. Hence, the success of crop improvement program depends upon the extent and magnitude of genetic variability available in the existing germplasms; exploration of genetic diversity in noug germplasms can open the door for crop improvement and provide relevant information for the scientific community. Germplasms collected from the diverse environment offers greater genetic diversity and may furnish useful traits to widen the genetic base of the crop. Local landraces are often heterogeneous and usually exhibit considerable genetic variation for desirable traits. Therefore, to exploit the genetic potential of the crop, understanding the morphological markers for better quality, high yielding and best agronomic traits is very essential. The present study was undertaken to assess the genetic diversity of Ethiopian noug genotypes in order to generate information on the status of genetic variation for further improvement and conservation program based on their morphological traits and oil content.

\section{Material and Methods}

\subsection{Description of the Study Area}

The experiment was carried out from June to December
2017 in the experimental field of Holetta Agricultural Research Center which is located $30 \mathrm{~km}$ west of Addis Abeba, $2400 \mathrm{~m}$ above sea level, $09^{\circ} 04^{\prime} \mathrm{N}$ and $38^{\circ} 30^{\prime} \mathrm{E}$. Holetta received $1144 \mathrm{~mm}$ annual rainfall and $6^{\circ} \mathrm{C}$ and $22^{\circ} \mathrm{C}$ minimum and maximum temperature respectively.

\subsection{Experimental Materials}

Two improved varieties from Holetta Agricultural Research Center High and Midland Oil Crops Improvement Program and 98 collections obtained from the Ethiopian Biodiversity Institute were used in this experiment. The genotypes were collected from different agro-ecologies representing the major noug growing regions of Ethiopia (Table 1).

\subsection{Experimental Design and Procedures}

The experiment was arranged in a $10 \times 10$ simple lattice design. Planting was done in a plot of three rows with $2 \mathrm{~m}$ length and $0.3 \mathrm{~m}$ spacing between rows and $0.6 \mathrm{~m}$ distance between plots with $8 \mathrm{~kg} / \mathrm{ha}$ of seed rate. The distance between the blocks was maintained to $3 \mathrm{~m}$. Fertilizer were applied at the recommended rate of $50 \mathrm{~kg} / \mathrm{ha}$ DAP and 30 $\mathrm{kg} / \mathrm{ha}$ urea [11] and other agronomic practices were done as required.

\subsection{Data Collection}

Data were collected based on standard noug agromorphological descriptors developed by Holetta Agricultural Research Center High and Midland Oil Crops Improvement Program of the Ethiopian Institute of Agricultural Research [12]. Days to $50 \%$ flowering (DF), days to $90 \%$ maturity (DM), grain filling period (GF), yield per plot (YPP), thousands seed weight (gm) and oil content were collected on plot basis. Whereas, number of primary branches (NPB), number of secondary branches (NSB), number of heads per plant $(\mathrm{NH})$, number of seeds per head $(\mathrm{NSH})$, number of seeds per plant (NSP) and plant height $(\mathrm{PH})$ were collected from randomly selected ten plants from the central row of each plot. For phonological data the number of days was calculated taking date of emergency as a reference.

\subsection{Statistical Analysis}

After checking for outliers and normality of residuals data were subjected to analysis of variance (ANOVA) using the SAS statistical package [13]. The significant difference among the genotypes was tested at 1 and $5 \%$ level of probability.

\subsection{Estimation of Variance Components}

The genotypic and phenotypic variances were estimated as described by Allard [14]. Phenotypic and genotypic coefficients of variation (PCV and GCV) were expressed as percentage of the corresponding phenotypic and genotypic standard deviations estimated as suggested by Johnson [15]. The PCV and GCV values were ranked as low $0-10 \%$, 
medium 10-20\% and $>20 \%$ high [16].

\subsection{Broad Sense Heritability $\left(\mathrm{H}^{2}\right)$}

Heritability in broad sense was computed as the percentage of genotypic to phenotypic variance and the heritability percentage categorized as low for less than 30\%, 30-60\% moderate and high if value is greater than or equal $(\geq) 60 \%$ [17].

\subsection{Genetic Advance (GA) and Genetic Advance as Percent of the Mean (GAM)}

Assuming selection of superior $5 \%$ of the genotypes was estimated in accordance with the method of Johnson and the GAM was categorized as $0-10 \%=$ low, $11-20=$ moderate and $>20 \%$ high [18].

\section{Results}

\subsection{Analysis of Variance (ANOVA) and Mean Performance of Genotypes}

The analysis of variance revealed highly significant difference $(\mathrm{P} \leq 0.01)$ among the genotypes for all the studied quantitative traits (Table 2). The studied genotypes showed wide range of variability for most of the traits evaluated in the study. A wide range of variability was observed for days to flowering ranged from 67 to 113 days with mean value 94.9 days. The number of primary branches per plant ranged from 4.2 to 25.5 with mean value of 11.9. Thousand seed weight ranged from 1.00 to 3.00 with a mean value of 1.8 .

The mean value of seed yield per plot recorded $102.8 \mathrm{gm}$ ranging from 96.2 to $110.4 \mathrm{gm}$.

Table 1. List of noug genotypes and their geographical origin tested at Holetta in 2017.

\begin{tabular}{|c|c|c|c|c|c|c|c|}
\hline Sr. No & Accession & Zone & Altitude & Sr. No & Accession & Zone & Altitude \\
\hline 1 & 15528 & Agew awi & 1650 & 51 & 15681 & East Gojam & 2420 \\
\hline 2 & 208396 & Agew awi & 1710 & 52 & 15686 & East Gojam & 2490 \\
\hline 3 & 15535 & Arssi & 2480 & 53 & 15692 & East Gojam & 2430 \\
\hline 4 & 15587 & Arssi & 2470 & 54 & 15693 & East Gojam & 2360 \\
\hline 5 & 216875 & Arssi & 2410 & 55 & 202242 & East Gojam & 1720 \\
\hline 6 & 15520 & Bahirdar special & 1680 & 56 & 202245 & East Gojam & 1800 \\
\hline 7 & 15746 & Bahirdar special & 1700 & 57 & 202254 & East Gojam & 1690 \\
\hline 9 & 15079 & Bale & 2430 & 59 & 202264 & East Gojam & 1820 \\
\hline 10 & 15560 & Bale & 2430 & 60 & 202266 & East Gojam & 1850 \\
\hline 11 & 208830 & Bale & 2430 & 61 & 202269 & East Gojam & 1700 \\
\hline 12 & 15092 & South Gonder & 1830 & 62 & 202270 & East Gojam & 1650 \\
\hline 13 & 200428 & South Gonder & 1700 & 63 & 202271 & East Gojam & 1845 \\
\hline 14 & 225962 & South Gonder & 2360 & 64 & 15683 & East Gojam & 2430 \\
\hline 15 & 225964 & South Gonder & 2370 & 65 & 208400 & East Gojam & 2400 \\
\hline 18 & 15781 & South Wollo & 2420 & 68 & 15056 & East Wellega & 1830 \\
\hline 19 & 15787 & South Wollo & 1700 & 69 & 15080 & East Wellega & 1820 \\
\hline 20 & 225954 & South Wollo & 2445 & 70 & 15574 & East Wellega & 2420 \\
\hline 21 & 225955 & South Wollo & 2450 & 71 & 15659 & East Wellega & 2480 \\
\hline 22 & 15008 & Illubabor & 1700 & 72 & 15617 & East Wellega & 1610 \\
\hline 23 & 15012 & Illubabor & 1700 & 73 & 15622 & East Wellega & 1840 \\
\hline 24 & 15115 & Jimma & 1740 & 74 & 15657 & East Wellega & 2410 \\
\hline 25 & 9978 & West Gojam & 1828 & 75 & 15660 & East Wellega & 2420 \\
\hline 26 & 15541 & West Gojam & 1800 & 76 & 15661 & East Wellega & 2430 \\
\hline 27 & 15697 & West Gojam & 1810 & 77 & 15662 & East Wellega & 2490 \\
\hline 28 & 15701 & West Gojam & 2440 & 78 & 15667 & East Wellega & 2480 \\
\hline 29 & 15054 & West Harerge & 1820 & 79 & 15668 & East Wellega & 2480 \\
\hline 30 & 208686 & West Harerge & 1770 & 80 & 15669 & East Wellega & 2460 \\
\hline 31 & 15018 & West Shewa & 1700 & 81 & 15671 & East Wellega & 2360 \\
\hline 32 & 15020 & West Shewa & 1800 & 82 & 208944 & East Wellega & 2460 \\
\hline 35 & 15066 & West Shewa & 1660 & 85 & 202454 & Oromia/kemise & 1730 \\
\hline 36 & 15083 & West Shewa & 2390 & 86 & 15543 & North Gondar & 1760 \\
\hline 37 & 15131 & West Shewa & 1800 & 87 & 15549 & North Gondar & 1770 \\
\hline 38 & 15132 & West Shewa & 1630 & 88 & 15721 & North Gondar & 1760 \\
\hline 39 & 15167 & West Shewa & 2390 & 89 & 15730 & North Gondar & 1800 \\
\hline 40 & 15202 & West Shewa & 1700 & 90 & 15733 & North Gondar & 1850 \\
\hline 41 & 15509 & West Shewa & 2390 & 91 & 214217 & North Gondar & 1620 \\
\hline 42 & 203184 & West Shewa & 2400 & 92 & 225966 & North Gondar & 1830 \\
\hline 43 & 203192 & West Shewa & 2470 & 93 & 15763 & North Shewa & 1850 \\
\hline 44 & 203194 & West Shewa & 2450 & 94 & 15765 & North Shewa & 1820 \\
\hline 45 & 203195 & West Shewa & 2430 & 95 & 202448 & North Shewa & 1620 \\
\hline 46 & 15154 & West Wellega & 1650 & 96 & 202461 & North Wollo & 1640 \\
\hline
\end{tabular}




\begin{tabular}{llllllll}
\hline Sr. No & Accession & Zone & Altitude & Sr. No & Accession & Zone & Altitude \\
\hline 47 & 202248 & East Gojam & 1700 & 97 & 202472 & North Wollo & 1735 \\
48 & 202258 & East Gojam & 1760 & 98 & 202473 & North Wollo & 1690 \\
49 & 15553 & East Gojam & 2450 & 99 & Shambu & Improved variety & \\
50 & 15680 & East Gojam & 2430 & 100 & Ginchi-1 & Improved variety \\
\hline
\end{tabular}

The oil content ranged from 26.5 to 43.0 with a mean value of $34.7 \%$. The mean comparisons between the performances of the genotypes showed that there are some genotypes superior over the improved varieties (Table 3). For all the studied traits the top five best out smart genotypes for different trait were constituted from different geographic origin (Table 1).

Table 2. Analysis of variance for 12 morphological traits of noug genotypes tested at Holetta in 2017.

\begin{tabular}{|c|c|c|c|c|c|c|}
\hline \multirow{2}{*}{ Traits } & \multicolumn{4}{|c|}{ Source of variations } & \multirow{2}{*}{ CV\% } & \multirow{2}{*}{ R-square } \\
\hline & MSR (1) ${ }^{d f}$ & MSB (18) & MSG (99) & MSE (81) & & \\
\hline DF & $0.72 \mathrm{~ns}$ & $15.19 \mathrm{~ns}$ & $233.68 * * *$ & 44.65 & 5.23 & 0.88 \\
\hline DM & $18.00 \mathrm{~ns}$ & $127.87 * * *$ & $66.07 * * *$ & 28.34 & 3.48 & 0.83 \\
\hline GFP & $11.52 \mathrm{~ns}$ & $164.99 * *$ & $164.72 * * *$ & 56.93 & 12.95 & 0.82 \\
\hline PH & $561.13 * *$ & $235.39 * * *$ & $206.14 * * *$ & 70.67 & 6.48 & 0.83 \\
\hline $\mathrm{NH}$ & $372.65^{* * *}$ & $22.52 *$ & $69.93 * * *$ & 11.12 & 15.53 & 0.86 \\
\hline NPB & $17.76^{* * *}$ & $5.01 * *$ & $1.63 * *$ & 0.96 & 12.99 & 0.79 \\
\hline NSB & $57.89 * * *$ & $4.78^{*}$ & $24.48 * * *$ & 4.65 & 13.67 & 0.80 \\
\hline NSH & $16.99 \mathrm{~ns}$ & $9.80 \mathrm{~ns}$ & $2147.91 * * *$ & 351.93 & 6.71 & 0.94 \\
\hline NSPP & $282.74 \mathrm{~ns}$ & $208.10 \mathrm{~ns}$ & $9883.17 * * *$ & 1148.41 & 11.41 & 0.94 \\
\hline YPP & 155.21 *** & $72.75 * * *$ & $26.18 * * *$ & 12.46 & 3.43 & 0.77 \\
\hline TSW & $4.59 * * *$ & $0.12 * * *$ & $0.15^{* * *}$ & 0.03 & 9.22 & 0.86 \\
\hline $\mathrm{OC}$ & $3.20 \mathrm{~ns}$ & $0.50 \mathrm{~ns}$ & $18.15 * *$ & 1.78 & 2.72 & 0.92 \\
\hline
\end{tabular}

$*$,** and *** Significant at $0.05,0.01$ and 0.001 probability level respectively and ns non-significant MSR $=$ Mean Square due to replication, MSB $=$ Mean Square due to block, $\mathrm{MSG}=$ Mean Square due to genotypes, $\mathrm{MSE}=$ Mean Square due to error, $\mathrm{CV} \%=$ Coefficient of variation in percentage. ()$^{\mathrm{df}}$ figures in parenthesis indicate degrees of freedom, $\mathrm{DF}=$ days to flowering, $\mathrm{DM}=$ days to maturity, $\mathrm{GFP}=\mathrm{Grain}$ filling period, $\mathrm{PH}=$ plant height, $\mathrm{NH}=$ number of heads, $\mathrm{NPB}=$ Number of primary branch, $\mathrm{NSB}=$ Number of secondary branch, NSPP $=$ Number of seed per plant, $\mathrm{YPP}=\mathrm{yield}$ per plot, $\mathrm{TSW}=\mathrm{Thousand}$ seed weight and $\mathrm{OC}=$ oil content.

Table 3. Elite genotypes identified on the basis of important morphological traits and oil content for future use.

\begin{tabular}{ll}
\hline Trait of interest & Genotypes identified \\
\hline Number of primary branch & $15781,225964,15066,15683$ and 225966 \\
Number of secondary branch & $15781,15787,214217,202245$ and \\
Number of head & 202254 \\
Number of seed per head & $154217,202461,15079,202473$ and 9978 \\
Number of seed per plant & $214217,15115,202245,202264$ and \\
Thousand seed weight & Ginchi-1 \\
Yield per plot & $15779,15709,214217,9978$ and 15012 \\
Oil content & Ghinchi-1 \\
\hline
\end{tabular}

\subsection{Phenotypic and Genotypic Coefficient of Variation}

Genotypic coefficient of variation, phenotypic coefficient of variation, heritability, genetic advance and genetic advance as the percent of the mean were presented in table 4. The highest PCV and GCV value were observed for traits such as number of head (78.2 and 72.3), number of seed per plant (65.8 and 61.9) and number of seed per head (63.6 and
58.2) and the lowest PCV and GCV values were recorded for yield per plot (3.5 and 2.6), number of primary branch (7.5 and 4.6) and days to maturity (3.7 and 2.8). The PCV values were found superior to the GCV for all the characters and the PCV value for oil content slightly larger than the GCV value.

\subsection{Broad Sense Heritability $\left(\mathrm{H}^{2}\right)$ and Genetic Advance under Selection (GA)}

The highest broad sense heritability value was recorded for oil content (90.1) followed by number of seed per plant (88.4). Low heritability scores were revealed for number primary branch (37.5) and yield per plot (52.7). Highest magnitudes for genetic advance (GA) were recorded for number of seed per plant (128.0) and number of seed per head (56.4) whereas, the lowest value was observed for thousand seed weight $(0.5)$, number of primary branch $(0.7)$ and yield per plot (3.9). On the other hand, genetic advance as percent of mean (GAM) at 5\% selection intensity was high for number of head (136.7) followed by number of seed per plant (119.8) but it was minimal for yield per plot (3.8) and days to maturity (4.4).

Table 4. Estimation of variance components for 12 quantitative traits of noug genotypes.

\begin{tabular}{llllllll}
\hline Traits & Mean \pm SD & Range & PCV & GCV & H $^{2}$ & GA & GAM \\
\hline DF & $94.9 \pm 12.8$ & $67.0-113.0$ & 11.4 & 10.2 & 80.9 & 18.0 & 19.0 \\
DM & $153.2 \pm 6.7$ & $138.0-165.8$ & 3.7 & 2.8 & 57.3 & 6.8 & 4.4 \\
GFP & $58.3 \pm 9.5$ & $35.5-86.5$ & 15.6 & 12.6 & 65.4 & 12.2 & 21.0 \\
PH & $129.7 \pm 10.6$ & $102.5-151.1$ & 7.8 & 6.3 & 65.7 & 13.7 & 10.6 \\
NH & $7.5 \pm 0.9$ & $5.5-10.0$ & 78.8 & 72.3 & 84.2 & 10.3 & 136.7 \\
NPB & $11.9 \pm 4.7$ & $4.2-25.5$ & 7.5 & 4.6 & 37.5 & 0.7 & 5.8 \\
\hline
\end{tabular}




\begin{tabular}{|c|c|c|c|c|c|c|c|}
\hline Traits & Mean \pm SD & Range & PCV & GCV & $\mathbf{H}^{2}$ & GA & GAM \\
\hline NSB & $21.5 \pm 6.5$ & $10.7-40.2$ & 16.2 & 14.6 & 81.1 & 5.8 & 27.1 \\
\hline $\mathrm{NSH}$ & $51.5 \pm 35.8$ & $1.7-181.3$ & 63.6 & 58.2 & 83.6 & 56.4 & 109.6 \\
\hline NSPP & $106.8 \pm 78.1$ & $3.5-399.8$ & 65.8 & 61.9 & 88.4 & 128.0 & 119.8 \\
\hline YPP & $102.8 \pm 3.1$ & $96.2-110.4$ & 3.5 & 2.6 & 52.7 & 3.9 & 3.8 \\
\hline TSW & $1.8 \pm 0.3$ & $1.0-3.0$ & 14.4 & 13.3 & 85.7 & 0.5 & 25.5 \\
\hline $\mathrm{OC}$ & $34.7 \pm 3.7$ & $26.5-43.0$ & 8.7 & 8.3 & 90.1 & 5.6 & 16.1 \\
\hline
\end{tabular}

$\mathrm{DF}=$ days to flowering, $\mathrm{DM}=$ days to maturity, $\mathrm{GFP}=$ Grain filling period, $\mathrm{PH}=$ plant height, $\mathrm{NH}=$ number of heads, $\mathrm{NPB}=\mathrm{Number}$ of primary branch, $\mathrm{NSB}=$ Number of secondary branch, $\mathrm{NSPP}=$ Number of seed per plant, $\mathrm{YPP}=$ yield per plot, TSW=Thousand seed weight and $\mathrm{OC}=$ oil $\mathrm{content}$; $\mathrm{SD}=$ standard deviation; $\mathrm{PCV}=$ phenotypic coefficient of variation, $\mathrm{GCV}=$ genotypic coefficient of variation, $\mathrm{H}^{2}=$ broad-sense heritability; $\mathrm{GA}=$ expected genetic gains and $\mathrm{GAM}=$ Genetic advance as percent of the mean

\section{Discussion}

The observed significant phenotypic variability among the evaluated noug genotypes implied that the underutilized genetic variability of the crop should be future priority in noug improvement and genetic conservation programs. The present result was in harmony with the previous findings which reported significant variation for number of heads, plant height, number of primary branches and number of secondary branches $[8,10]$. Likewise highly significant variability was reported for days to $50 \%$ flowering, days to maturity, 1000 seed weight, oil content (\%) and seed yield per plant [19]. The wide range of variation observed among the genotypes for the studied traits revealed that there is an opportunities for genetic improvement through selection of superior genotypes or cross breeding.

Quantitative traits such as yield are controlled by many genes and highly influenced by environmental factors. Therefore, GCV, PCV, H, GA and GAM help to group variability into heritable and non-heritable components. The high PCVs and GCVs indicate the presence of high genetic variations among the tested genotypes for the studied traits. Based on the result the highest PCV and GCV value for number of head, number of seed per plant and number of seed per head showed that selection of these traits based on phenotype may be useful for yield improvement. High GCV and PCV for number of heads and number of seed per head and lowest GCV and PCV value for number of primary branch were reported [20, 21]. In addition high GCV for number of head were reported $[10,22,23]$ which is in harmony with the present result and lowest GCV for number of primary branch was reported [24]. The superior PCV values over the GCV for all the traits indicate the influence of environment for traits expression. However the PCV value for oil content slightly larger than the GCV value; indicating very little influence of environment for their expression than the other traits and the trait is stable in its expression.

Heritable variation is useful for permanent genetic improvement. Highest heritability have been reported for number of heads, oil content and number of seed per plant $[21,24,25]$. Similarly low heritability score have been reported for number primary branch [22], yield per plot and days to maturity [10]. Low heritability result could be due to high environmental effect; along with low phenotypic and genotypic coefficients of variations of these traits, indicating limited possibility of improvement for those characters through selection because of high environmental effect. According to the heritability class number of primary branch, yield per plot and days to maturity grouped as moderately heritable $(30-60 \%)$ traits but the rest were categorized as highly heritable traits $(\geq 60 \%)$. Even though heritability determines the effectiveness of selection; estimating alone is not sufficient for selection criteria. Hence, to increase selection efficiency estimating of heritability and genetic advance should always be considered simultaneously [15].

High heritability estimates along with high genetic advance is usually more helpful in predicting gain under selection than heritability estimates alone. The range of GAM was classified as low less than $10 \%, 10-20 \%$ moderate and greater than $20 \%$ high [15]. Therefore, based on this demarcation; days to maturity, number of primary branch and yield per plot showed low GAM. While, days to flowering, plant height and oil content exhibited moderate value but other traits were grouped as high. In this study, high genetic advance along with high heritability was shown by number of seed per plant, number of seed per head and number of heads indicating the predominance of additive gene action for these characters. Hence, the improvement of these traits could be made through direct phenotypic selection. The result was in agreement with the previous reports $[20,24]$. Similar finding for number of seed was reported $[19,21]$. In other finding, similar result was reported [22] for number of heads. While in earlier report contradictory result high heritability coupled with high genetic advance for number of secondary branches per plant and plant height was reported [19].

On the other hand moderate heritability coupled with low genetic advance for number of primary branch, yield per plot and Days to maturity suggesting that environment had major role in their expression of these traits. Therefore, heterosis or recurrent breeding may be beneficial to improve these traits. High heritability coupled with low genetic advance was observed for oil content, thousand seed weight and days to flowering suggesting that predominance of non-additive gene action. Similar result was reported for thousand seed weight [22] and for oil content [20]. However, the report conflict with previous study who report high value for heritability coupled with high genetic advance for oil content [25]. The variations may be because of the environment influence on the expression of the traits and the genetic difference between the genotypes.

In order to achieving high expected genetic gain from selection of individuals; the present study clearly indicates 
the significance of considering the interrelation of components than depending exclusively on one way. According to this result traits with high GCV and high $\mathrm{H}^{2}$ resulted in high expected GA as compared to traits with low GCV and $\mathrm{H}^{2}$.

\section{Conclusion}

Besides its importance noug improvement is lag behind and little were known about the diversity states of Ethiopian accessions. The study concludes the existence of genetic diversity among noug genotypes that can be beneficial for improvement. Number of head, number of seed per head and number of seed per plant exhibited high values of phenotypic and genotypic coefficient of variation, broad sense heritability and genetic advance. Thus, these traits can be considered as favorable attributes for noug improvement through effective phenotypic selection. On the other hand days to maturity, number of primary branch and yield per plot recorded lowest heritability and genetic advance; hence, improvement of these trait relay on either heterosis breeding or recurrent selection. Therefore, the information will be useful in future noug breeding and conservation programs.

\section{Conflict of Interest}

All the authors do not have any possible conflicts of interest.

\section{Acknowledgements}

The authors gratefully acknowledge the financial support from Ethiopian Institute of Agricultural Research (EIAR) for this study. We would also like to thank Ethiopian Institute of Biodiversity for providing noug accessions and to Holetta Agricultural Research Center National High and Midland Oilseeds Improvement Program technicians who assisted the research in the field.

\section{References}

[1] CSA, 2019. The Federal Democratic Republic of Ethiopia Central Statistical Agency Agricultural sample survey report on area and production of major crops (private peasant holdings, Meher season) statistical bulletin 589 Addis Ababa, Ethiopia.

[2] Adarsh, M. N., Poonam, K. and Shilpa, D., 2014. A review of Guizotia abyssinica : A multi-purpose plant with an economic prospective. Journal of Industrial Pollution Control. 30 (2): $277-280$.

[3] Dempewolf, H., Tesfaye, M., Teshom, A., Bjorkman, A. D., Andrew, R. L., Scascitelli, M., Black, S., Bekele, E., E., Engels, J. M., Cronk, Q. C. and Rieseberg, L. H., 2015. Patterns of domestication in the Ethiopian oilseed crop noug (Guizotia abyssinica). Evolutionary Applications. 8 (5): 464475. Doi: $10.1111 /$ eva.12256.

[4] Bhandari, H. R., Bhanu, A. N., Srivastava K., Singh M. N., Shreya, 2017. Assessment of genetic diversity in crop plants.
An Overview. Advance Plants Agricultural Research. 7 (3): 00255 .

[5] Mustafa, K., Mohammad, H. and Mohammad, M., 2011. Genetic diversity of wheat genotype based on cluster and principal component analyses for breeding strategies. Australian Journal of Crop Science. 5 (1): 17-24.

[6] Aremu, C. O., 2011. Genetic diversity: A review for need and measurements for inter species crop improvement. Journal of Microbial Biotech Research. 1 (2): 80-85.

[7] Fu Yong BI., 2015. Understanding crop genetic diversity under modern Plant Breeding. Theoretical and Applied Genetics. 128 (11): 2131-2142.

[8] Ekhlaque, A., Singh, M. K., Paul, A., Ansari, A. M. and Singh, D. N., 2016. Genetic studies of yield and yield component of noug (Guizotia abyssinica (L. F.) Cass.) in rain fed condition of western plateau of Jharkhand. International Journal of Tropical Agriculture. 34 (4): 1127-1133.

[9] Teklewold, A. and Wakjira, A., 2004. Seed filling and oil accumulation in noug (Guizotia abyssinica (L. f.) Cass). Sinet Ethiopian Journal of Science. 27 (1): 25-32.

[10] Patil, H. E., Mali, R. S., Giri, A. R. and Thawari, S. B., 2013. Genetic improvement in noug (Guizotia abyssinica (L. f.) Cass) by using study of variability, correlation and path analysis. International Journal of Agricultural Sciences. 9 (2): 671-673.

[11] MOA, 2014. Oil crops production Manual. Addis Ababa, Ethiopia.

[12] Getinet, A. and S. M. Sharma. 1996. Niger (Guizotia abyssinica (L. f.) Cass.) Promoting the conservation and use of underutilized and neglected crops. Institute of Plant Genetics and Crop Plant Research, Gatersleben/International Plant Genetic Resources Institute, Rome.

[13] SAS Institute, 2010. SAS/STAT Guide for Personal Computers, Version 13.1 editions. Cary, N. C., SAS Institute Inc.

[14] Allard, R. W., 1960. Principles of Plant Breeding. John Willey and sons, Inc. New York.

[15] Johnson, H. W., H. F. Robinson and R. E. Comstock, 1955. Estimates of genetic and environmental variability in soya beans. Agronomy Journal. 47: 314-318.

[16] Sivasubramanian, S. and Menon, M., 1973. Heterosis and inbreeding depression in rice. Madras Agricultural Journal. 60 (7), 1139-1140.

[17] Robinson, H. F., Comstock, R. E. and Harvey, P. H., 1949. Estimates of heritability and the degree of dominance in corn. Agronomy Journal.

[18] Dempewolf, H., Kane, N. C., Ostevik, K. L., Geleta, M., Barker, M. S., Lai, Z., Stewart, M. L., 2010. Establishing genomic tools and resources for Guizotia abyssinica (L. f.) Cass: the development of a library of expressed sequence tags, microsatellite loci and the sequencing of its chloroplast genome. Molecular Ecology Resources. 10: 1048-1058.

[19] Kumar, V., 2016. Morphological characterization and genetic analysis for yield and quality traits in noug. MSc Thesis College of Agriculture, Jabalpur Jawaharlal Nehru Krishi Vishwa Vidyalaya Jabalpur, MP. 
[20] Pulate, S. C., Patil, H. S. and Patil, M. R., 2013. Multivariate analysis of genetic among noug genotypes in relation to seed oil quality traits. The Bio scan. 8 (3): 829-833.

[21] Bisen, R., Panday, A. K., Jain, S. and Sahu R., 2015. Genetic analysis in noug (Guizotia abyssinica (L. F.) Cass.) germplasm. Progressive Research. 10 (3): 1536-1539.

[22] Thakur, S. K. and Reddy, R. K., 2012. Genetic variability, correlation and path analysis in noug (Guizotia abyssinica Cass). Journal of Oilseeds Research. 29 (1): 31-33.

[23] Jagtap, P. K., Sandipan, P. B., Patel, K. M. and Patel, M. C.,
2014. Interrelationship between yield and yield attributing traits in noug germplasm. Trends in Biosciences. 7 (16): 21352136.

[24] Panda, S. and Sial, P., 2012. Assessment of existing genetic variability and yield component analysis in noug (Guizotia Abyssinica (L. f.) Cass). Indian Journal of Innovations Development. 1 (7): 511-514.

[25] Khuntey, Y., Kumar, N. and Mishra, S. P., 2015. Assessment of genetic variability and yield component analysis in noug (Guizotia abyssinica L.) genotypes. Indian Research Journal Genetics and Biotech. 7 (1): 123-126. 